\title{
Association between the circulating leptin levels and the biomarkers of oxidative stress and inflammation among Iranian overweight and obese adults
}

\author{
Nahid Aboutaleb ${ }^{1}$, Mitra Zarrati ${ }^{2}$, Elhameh Cheshmazar ${ }^{2}$, Raheleh Shokouhi Shoormasti ${ }^{3}$, \\ Elham Razmpoosh ${ }^{4,5}$, Farinas Nasirinezhad ${ }^{6 *}$ \\ Received: 6 Feb $2017 \quad$ Published: 16 Dec 2017
}

\begin{abstract}
Background: Oxidative stress in obese people is an important pathogenic mechanism of an obesity-associated metabolic syndrome. We evaluated the association between circulating leptin levels with biomarkers of oxidative stress in overweight and obese participants. Methods: This study was performed on 189 overweight and obese people aged 18-60 years old. Serum leptin, superoxide dismutase (SOD), high-sensitivity C-reactive protein (hs-CRP), homocysteine (Hcy), thiobarbituric acid reactive substances (TBARS) and amyloid A (SAA) concentrations were measured. Pearson correlation and multiple linear regressions were used to assess the relationships.

Results: We found that among the biomarkers of oxidative stress and inflammation in participants, serum hs-CRP and SAA were positively correlated with $\mathrm{BMI}(\beta=0.003, \mathrm{P}<0.001$ and $\beta=7.83, \mathrm{P}<0.001$, respectively $)$. This relationship remained significant even after controlling other oxidative stress and inflammatory indicators $(\beta=0.003, \mathrm{p}<0.001$ for hs-CRP), but this association disappeared for SAA. In addition, serum hs-CRP was positively correlated with leptin $(\beta=0.001, p=0.003)$. Regression analysis showed that there was no association between serum Hcy, SAA, TBARS and SOD with serum leptin concentrations

Conclusion: Overall, the current study demonstrated that serum hs-CRP and SAA levels were independently correlated with BMI. Furthermore, serum hs-CRP was positively correlated with leptin. Focusing on such strategies may lead to promises for alleviating obesity and its co-morbidities.
\end{abstract}

Keywords: Leptin, Obesity, Oxidative stress, Inflammation

Copyright $\odot$ Iran University of Medical Sciences

Cite this article as: Aboutaleb N, Zarrati M, Cheshmazar E, Shokouhi Shoormasti R, Razmpoosh E, Nasirinezhad F. Association between the circulating leptin levels and the biomarkers of oxidative stress and inflammation among Iranian overweight and obese adults. Med J Islam Repub Iran. 2017 (16 Dec);31:81. https://doi.org/10.14196/mjiri.31.81

\section{Introduction}

Obesity is a chronic disease with different origins that derives from the interaction of social, behavioral, psychological, metabolic, cellular, and molecular factors (1). Reactive oxygen species (ROS) are produced under physiological conditions and responsible for direct or indirect tissue damages in many diseases. Thus, oxidative stress is involved in pathological processes such as obesity, diabetes, cardiovascular disease (CVD) and atherogenicity (2). Previous studies have shown that due to the depletion

Corresponding author: Dr Farinas Nasirinezhad, nasirinezhad.f@iums.ac.ir

1. Physiology Research Center and Physiology Department, Faculty of Medicine Iran University of Medical Sciences, Tehran, Iran.

2. Faculty of Nutrition, School of Public Health, Iran University of Medical Sciences, Tehran, Iran.

3. Immunology, Asthma and Allergy Research Institute, Tehran University of Medical Sciences, Tehran, Iran.

4. Nutrition and Food Security Research Center, Shahid Sadoughi University of Medical Sciences, Yazd, Iran.

${ }^{5}$ Department of Nutrition, Faculty of Health, Shahid Sadoughi University of Medical Sciences, Yazd, Iran.

6. Physiology Research Center and Physiology Department, Faculty of Medicine, Iran University of Medical Sciences, Tehran, Iran. of antioxidant sources like superoxide dismutase (SOD), susceptibility to oxidative damage is even greater in obese subjects (3). SOD is an enzyme that participates in antioxidant defense in nearly all living cells exposed to oxygen(4). In the general population, thiobarbituric acid reactive substances (TBARS) concentrations are an important parameter of systemic oxidative stress (5), which is associated with various factors including age, body mass index (BMI), glucose and lipid metabolism (6).

$\uparrow$ What is "already known" in this topic:

Oxidative stress in obesity is an important pathogenic mechanism of endothelial injuries caused by inflammation.

$\rightarrow$ What this article adds:

hs-CRP has a positive correlation with leptin concentration in obese people and is resulted in the effects of leptin induced inflammatory factors. 
Surveys demonstrated subjects with visceral fat accumulation had significantly higher levels of circulating TBARS (5). Visceral adiposity correlates with systemic levels of oxidation; so it seems that fat accumulation parallels with ROS production (5). In addition, serum amyloid A (SAA) has produced from adipose tissue, offering a novel link between enhanced adipose tissue mass and the lowgrade inflammatory state in which can be seen in obesity $(7,8)$. On the other hand, although alteration in homocysteine (Hcy) levels has not been well-demonstrated in obese subjects, they lean to be suffering from metabolic syndrome (MS) signs. In turn it could be linked with increased levels of Hcy, as well as nutritional deficiencies of folate, pyridoxine or cobalamin that may lead to total higher levels of homocysteine in blood of obese subjects $(9$, 10). Also, high-sensitivity C-reactive protein (hs-CRP) which is raised in an inflammatory state, such as obesity, is seen as a strong independent predictor and risk factor for cardiovascular diseases (11).

In fact, there have been no published cross-sectional studies in Iran that have evaluated the association between leptin levels and the biomarkers of oxidative stress and inflammation among Iranian overweight and obese adults.

Therefore, in this study, we assessed the levels of TBARS, SOD (biomarkers of oxidative stress) and SAA, hs-CRP, homocysteine (inflammation biomarkers). Also, the relationship between circulating serum levels of leptin and BMI with biomarkers of oxidative stress and inflammation in overweight and obese people were evaluated.

\section{Methods}

\section{Participants}

This study was a cross-sectional study desgned and implemented in Tehran, Iran. Subjects were selected from people who referred to the clinical nutrition department in Iran University of Medical Sciences (IUMS). The individuals were excluded from the study if they had inflammatory or infectious diseases, cancer, secondary causes of obesity, pregnancy or breastfeeding, menopause, severe hepatic or renal disease and using medication, including anti-hypertensive drugs, hypoglycemic and hypolipidemic agents, using of NSAIDS or other inflammatory drugs and use of nutrition supplements. The study group comprised one hundred eighty-nine Iranian adult men and women aged 18-60 years old who were recruited for the study among the eligible ones. The participants were divided into three groups based on their BMI $\left(\mathrm{kg} / \mathrm{m}^{2}\right)$ : Normal group: $18.5<\mathrm{BMI}<24.9$, overweight: $25<\mathrm{BMI}<29.5$ and obese group: $\mathrm{BMI}>30$. Sample size was calculated using the below formula (12):

$$
\begin{gathered}
N=\left[\frac{Z \alpha+Z \beta}{C}\right]^{2}+3 \\
Z \alpha=1.960 \\
Z \beta=0.842 \\
C=0.5 * \ln [(1+r) /(1-r)]=0.203 \\
r(\text { correlation coefficient })=0.2
\end{gathered}
$$

\section{Ethics statements}

This study was performed according to the principles of the Declaration of Helsinki and the study protocol (Ethic No: 90-03-27-14124) and was approved by the ethics committee of IUMS. Informed consent form and 24-hour recall were obtained from all subjects after explaining the purpose and nature of the study to them.

\section{Assessment of anthropometric measurements}

Body weight was measured to the nearest $0.1 \mathrm{~kg}$ on calibrated scales (OMRON, HBF-516-Japan). Height was quantified to the nearest $0.5 \mathrm{~cm}$. The circumference of the hip was measured at the greatest protuberance of the buttocks and waist circumference was measured as a minimum circumference between the iliac crest and the rib cage while the participant's worn indoor clothes and barefoot. BMI was defined as weight in kilograms $(\mathrm{kg})$ divided by height in meters squared $\left(\mathrm{m}^{2}\right)$.

\section{Biochemical measurements}

Fasting venous blood $(10 \mathrm{~mL})$ was collected from subject after fourteen hours of fasting period and kept in vacutainer tubes. Blood were divided into two heparinized and non heparinized tube. To separate serum, blood samples were immediately centrifuged. The samples were then stored at $-80^{\circ} \mathrm{C}$ before analysis. Leptin concentrations were determined by the use of the ELISA Kit (eBioscience, USA) with inter- and intra-assay coefficient variances (CVs) of 6.7 and $8.9 \%$, respectively and SOD was measured by the ELISA method using related kits (MyBioSource, USA) with inter- and intra-assay CVs of 6.7 and $8.9 \%$, respectively. The levels of hs-CRP were assessed by the turbidometric method (Pars azmoon, Tehran, Iran) with inter- and intra-assay CVs of 6.7 and $8.9 \%$, respectively. Plasma Hcy was assessed using high-performance liquid chromatography (HPLC) with colorimetric electrochemical detection with inter- and intra-assay CVs of 6.7 and $8.9 \%$, respectively. TBARS levels were measured using the colorimetric technique as described by Uchiyama and Mihara (13) with inter- and intra-assay CVs of 6.7 and $8.9 \%$, respectively and SAA levels were measured using high-sensitivity method (ELISA) with a BNII analyser (Dade Behring) with previously validated techniques (14) with inter- and intra-assay CVs of 6.7 and $8.9 \%$, respectively.

\section{Statistical analysis}

Statistical analysis was performed using SPSS software (version 18.0; SPSS Inc., Chicago, IL, USA). The Kolmogorov-Smirnov test was used for evaluation of normal distribution of quantitative variables. Descriptive statistics, Mean \pm SD and median (Q1, Q3) were calculated for variables with normal and non-normal distribution, respectively. Logarithmic transformation was performed for some variables with non-normal distribution. We performed Pearson correlations and multiple regression analysis to assess the relationship between variables. TBARS, SAA, Hcy, hs-CRP and SOD were considered as dependent variables. Leptin and BMI were considered as independent variables. $\mathrm{P}$ value $<0.05$ was considered statistically significant. 


\section{Results}

The study included 84 (44.4\%) men and 105 (55.6\%) women with an average age of $37.49 \pm 10.28$ years. Mean weight and BMI were $79.62 \pm 17.96 \mathrm{~kg}$ and $29.16 \pm 5.8$ $\mathrm{kg} / \mathrm{m}^{2}$, respectively. Data on the anthropometric characteristics of participants were presented in Table 1.

Our study demonstrated that serum hs-CRP ( $\mathrm{r}=0.551$, $\mathrm{P}<0.0001)$ and SAA levels $(\mathrm{r}=0.403, \mathrm{p}<0.001)$ was significantly associated with BMI (Table 2). Pearson correlation analysis revealed that there was no association between Hcy, TBARS and SOD with BMI. Likewise, no association between Hcy, hs-CRP, SAA, TBARS and SOD with leptin was observed.

Simple linear regression analysis demonstrated that among the biomarkers of oxidative stress and inflammation in participants, serum hs-CRP and SAA were positively correlated with BMI $(\beta=0.003, P<0.001$ and $\beta=7.83$, $\mathrm{p}<0.001$, respectively) (Table 3 ). This relationship remained significant even after controlling for other oxidative stress and inflammatory indicators for hs-CRP $(\beta=0.003$, $\mathrm{p}<0.001$ ), but this association disappeared for SAA. In addition, serum hs-CRP was positively correlated with leptin $(\beta=0.001, p=0.003)$. Regression analysis showed that there was no association between serum Hcy, SAA, TBARS and SOD with serum leptin concentrations.

\section{Discussion}

This study was aimed to assess the associations between biomarkers of oxidative stress and inflammation in overweight and obese subjects. The current study demonstrated that serum hs-CRP and SAA levels were associated with BMI among overweight and obese subjects. Our findings

Table 1. Baseline characteristics of participants

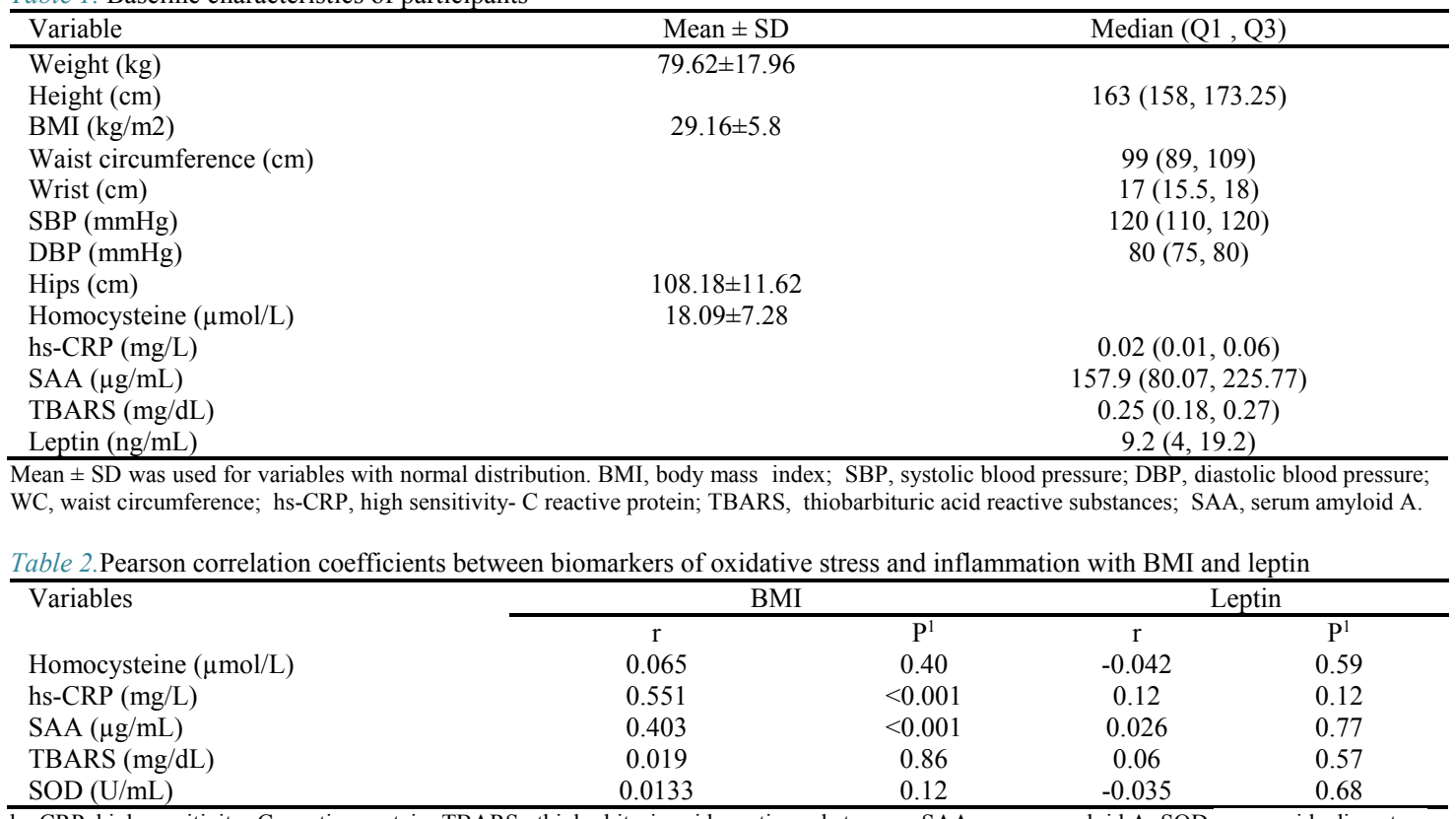

hs-CRP, high sensitivity- $C$ reactive protein; TBARS, thiobarbituric acid reactive substances; SAA, serum amyloid A; SOD, superoxide dismutase.

${ }^{1}$ Obtained from Pearson's correlation analysis.

Table 3. Multiple regression analysis between biomarkers of oxidative stress and inflammation with BMI and leptin

\begin{tabular}{|c|c|c|c|c|c|c|}
\hline & \multicolumn{3}{|c|}{ BMI } & \multicolumn{3}{|c|}{ Leptin } \\
\hline & $\beta$ & $95 \% \mathrm{CI}$ & $\mathrm{P}^{1}$ & $\beta$ & $95 \% \mathrm{CI}$ & $\mathrm{P}^{1}$ \\
\hline Homocysteine $(\mu \mathrm{mol} / \mathrm{L})$ & & & & & & \\
\hline Crude & 0.079 & $-0.108,0.267$ & 0.40 & 0.009 & $-0.078,0.096$ & 0.84 \\
\hline $\begin{array}{l}\text { Adjusted }^{2} \\
\text { hs-CRP (mg/L) }\end{array}$ & 0.222 & $-0.133,0.576$ & 0.21 & 0.035 & $-0.075,0.145$ & 0.52 \\
\hline Crude & 0.003 & $0.003,0.004$ & $<0.001$ & 0.001 & $0.00,0.001$ & 0.003 \\
\hline Adjusted & 0.003 & $0.002,0.005$ & $<0.001$ & 0.000 & $-0.001,0.00$ & 0.65 \\
\hline $\mathrm{SAA}(\mu \mathrm{g} / \mathrm{mL})$ & & & & & & \\
\hline Crude & 7.83 & $3.99,11.67$ & $<0.001$ & 0.219 & $-1.70,2.14$ & 0.82 \\
\hline $\begin{array}{l}\text { Adjusted } \\
\text { TBARS (mg/dL) }\end{array}$ & 2.08 & $-7.2,11.36$ & 0.65 & -0.581 & $-3.40,2.24$ & 0.68 \\
\hline Crude & 0.00 & $-0.002,0.003$ & 0.87 & 0.00 & $-0.001,0.001$ & 0.91 \\
\hline $\begin{array}{l}\text { Adjusted } \\
\text { SOD }(\mathrm{U} / \mathrm{mL})\end{array}$ & -0.001 & $-0.005,0.002$ & 0.44 & 0.00 & $-0.001,0.001$ & 0.68 \\
\hline Crude & 0.001 & $0.00,0.002$ & 0.19 & 0.00 & $0.00-0.001$ & 0.74 \\
\hline Adjusted & 0.00 & $-0.002,0.001$ & 0.71 & 0.00 & $0.00-0.001$ & 0.36 \\
\hline
\end{tabular}

hs-CRP, high sensitivity- C reactive protein; TBARS, thiobarbituric acid reactive substances; SAA, serum amyloid A; SOD, superoxide dismutase.

${ }^{1}$ Obtained from multiple regression analysis.

${ }^{2}$ After controlled mutual effect of other biochemical indicators as covariates. 
also indicated that serum hs-CRP levels were positively correlated with leptin.

Obesity has a dominant role in serum leptin levels (15). It has been proven that increased levels of serum leptin are accompanied with high BMI and the acute degree of obesity (15). But our results did not show any significant association between leptin and BMI ranges. Also in the present study, we failed to find an association between serum Hcy levels and BMI as well as leptin. Tungtrongchitr et al. (16) observed that there were higher levels of Hcy in overweight subjects compared with normal weight subjects. In addition, Vay'a et al. (10) demonstrated that morbidly obese patients had higher Hcy levels than non-obese subjects. In other words, this increase is related with anthropometric, inflammatory and metabolic parameters in obese people (10). In another study by Narin et al. (17) Hcy levels were increased in obese subjects with hyperleptinemia. Gallistl et al. (9) indicated that BMI was also significantly correlated with Hcy levels. Hcy has been implicated in promoting atherosclerotic and thrombotic vascular diseases (24). It has been revealed that Hcy can induce endothelial cell injury, which largely results in the generation of reactive oxygen species (16). Leptin resistance, which is associated with hyperleptinemia is common in obese individuals (18). Leptin induces oxidative stress in endothelial cells (19) and Hcy also seems to induce oxidative stress. So, an increase in Hcy levels was observed in obese subjects with hyperleptinemia (20). This inconsistency between our study and others may explain due to the differences in age groups, the health status of volunteers and evaluation methods.

Our data indicated that hs-CRP levels were positively correlated with BMI and leptin. Our findings were in consistent with previous results showing that BMI was the adiposity factor and strongly correlated with serum hsCRP concentrations (21-23). In addition, visceral fat area and waist circumference were strongly correlated with hsCRP levels (24). Our findings were in accordance with observed results by Sanip et al.(25). They have reported that hs-CRP levels were positively correlated with weight, BMI, waist circumference, hip circumference, body fat and visceral fat in obese females(25). The precise mechanism whereby obesity or adipose tissue accumulation contributed to elevated hs-CRP levels remain to be sustained; however, a solid relationship has been demonstrated between adipocytokines such as interleukin 6 (IL-6) and other inflammatory markers in obese women. It is also suggested that cytokines secreted by adipose tissue in obese subjects could play a role in the high secretion of inflammatory proteins in liver (26).

The results of our study indicated that serum SAA concentrations were associated with BMI. Several studies have reported that obese individuals tend to have increased levels of SAA compared with lean individuals, and they have also accounted that SAA expression is correlated with BMI and fat cell size (27-29). In a study by Lappalainen et al. (8) was observed that there was a relationship between serum SAA concentrations and leptin in obese subjects. Both SAA and leptin are predominantly expressed in adipocytes, which may in part explain this association (30). However, our findings did not show any association between SAA and serum leptin concentrations. The findings of the current study did not support the research conducted by Poitou and Viguerie (31), who reported the overproduction of SAA in adipose tissue among obese subjects with a functional leptin receptor and leptin receptor-mutated subjects. The overexpression of SAA in leptin receptor-mutated subjects can be explained in part by the extreme early onset of adiposity as outgrows due to the absence of leptin signaling (31).

Surprisingly, this study did not show any significant relation between serum TBARS levels and BMI as well as leptin. Previous findings indicated that obese people have higher TBARS levels $(32,33)$. This inconsistency between our study and others may have been due to the differences in evaluation methods. TBARS assay is widely used as an indirect indicator of lipid peroxidation and can be applied for the measurement of oxidative stress (34). Low levels of antioxidants in obesity is associated with an increase in endogenous production of lipid peroxides as well as the depletion of antioxidant compounds in plasma (33). Okauchi et al. (5) demonstrated that subjects with visceral fat accumulation have high levels of TBARS.

Our results demonstrated that there was not any significant relation between serum SOD levels and BMI as well as leptin. In a study by Tungtrongchitr et al. (35) was seen that SOD activity was lower in overweight people compared with normal-weight individuals. Obesity is directly associated with high levels of leptin (36). Adverse effects of leptin may lead to the increase of oxidative stress, which is mediated by activation of NADPH oxidase (37).

Antioxidant enzymes play a major role in ROS scavenging (38). SOD is an important defensive antioxidant in nearly all living cells that is exposed to oxygen (39).

The potential feature of our study was the large sample size, but the limitation of this study was that this analysis was performed only in overweight and obese adults indicating that these results cannot be applied to healthy-weight adults. Another limitation of our study is the lack of measurement of visceral fat.

\section{Conclusion}

Overall, the current study demonstrated that serum hsCRP and SAA levels were independently correlated with BMI. Furthermore, serum hs-CRP was positively correlated with leptin. Consequently, as enduring extent of obesity and its co-morbidities is increasing at an alarming rate, focusing on such strategies may lead to promises for alleviating non communicable diseases, by modifying the oxidative stress and inflammation biomarkers. Yet, further studies are needed to confirm our findings and determine possible underlying mechanisms.

\section{Acknowledgements}

The authors thank the participants in the study for their important contributions. We also appreciate Soraya Mehrabi and Somayeh Dashti for their assists in the experimental procedure. 


\section{Funding}

This study was funded by Iran University of Medical Sciences [grant no. 94022726191].

\section{Ethical approval}

All procedures performed in studies involving human participants were in accordance with the ethical standards of the institutional and/or national research committee and with the 1964 Helsinki declaration and its later amendments or comparable ethical standards.

\section{Informed consent}

Informed consent was obtained from all individual participants included in the study.

\section{Conflict of Interests}

The authors declare that they have no competing interests.

\section{References}

1. Fernández-Sánchez A, Madrigal-Santillán E, Bautista M, Esquivel-Soto J, Morales-González Á, EsquivelChirino $\mathrm{C}$, et al. Inflammation, oxidative stress, and obesity. Int. J. Mol. Sci. 2011;12(5):3117-32.

2. Esposito K, Ciotola M, Schisano B, Misso L, Giannetti $\mathrm{G}$, Ceriello A, et al. Oxidative stress in the metabolic syndrome. J Endocrinol Invest. 2006;29(9):791-5.

3. Ozata M, Uckaya G, Aydin A, Isimer A, Ozdemir I. Defective antioxidant defense system in patients with a human leptin gene mutation. Horm Metab Res. 2000;32(07):269-72.

4. Lobo V, Patil A, Phatak A, Chandra N. Free radicals, antioxidants and functional foods: Impact on human health. Pharmacogn Rev. 2010;4(8):118.

5. Okauchi Y, Kishida K, Funahashi T, Noguchi M, Ogawa $\mathrm{T}$, Okita $\mathrm{K}$, et al. Cross-sectional and longitudinal study of association between circulating thiobarbituric acidreacting substance levels and clinicobiochemical parameters in 1,178 middle-aged Japanese men-the Amagasaki Visceral Fat Study. Nutr Metab . 2011;8(1):1.

6. Whitfield J. Gamma glutamyl transferase. Crit Rev Clin Lab Sci. 2001;38(4):263-355.

7. Sjöholm K, Palming J, Olofsson LE, Gummesson A, Svensson PA, Lystig TC, et al. A microarray search for genes predominantly expressed in human omental adipocytes: adipose tissue as a major production site of serum amyloid A. J Clin Endocrinol Metab. 2005;90(4):2233-9.

8. Lappalainen T, Kolehmainen M, Schwab U, Pulkkinen L, Laaksonen D, Rauramaa R, et al. Serum concentrations and expressions of serum amyloid A and leptin in adipose tissue are interrelated: the Genobin Study. Eur J Endocrinol. 2008;158(3):333-41.

9. Gallistl S, Sudi K, Mangge H, Erwa W, Borkenstein M. Insulin is an independent correlate of plasma homocysteine levels in obese children and adolescents. Diabetes care. 2000;23(9):1348-52.

10. Vayá A, Rivera L, Hernández-Mijares A, de la Fuente M, Solá E, Romagnoli M, et al. Homocysteine levels in morbidly obese patients. Its association with waist circumference and insulin resistance. Clin Hemorheol Microcirc. 2012;52(1):49-56.

11. Yan E, Chen S, Hong K, Kim WS, Bajpai A, Treyzon $\mathrm{L}$, et al. Insulin, hs-CRP, leptin, and adiponectin. An analysis of their relationship to the metabolic syndrome in an obese population with an elevated waist circumference. Int J Obes (Lond). 2008;6(1):64-73.

12. Okauchi Y, Kishida K, Funahashi T, Noguchi M, Ogawa T, Okita K, et al. Cross-sectional and longitudinal study of association between circulating thiobarbituric acid-reacting substance levels and clinicobiochemical parameters in 1,178 middle-aged Japanese men-the Amagasaki Visceral Fat Study. Nutr Metab . 2011;8(1):82.

13. Uchiyama $M$, Mihara $M$. Determination of malonaldehyde precursor in tissues by thiobarbituric acid test. Anal Biochem. 1978;86(1):271-8.

14. Rifai N, Joubran R, Yu H, Asmi M, Jouma M. Inflammatory markers in men with angiographically documented coronary heart disease. clin chem. 1999;45(11):1967-73.

15. Arnardottir E, Maislin G, Jackson N, Schwab R, Benediktsdottir B, Teff K, et al. The role of obesity, different fat compartments and sleep apnea severity in circulating leptin levels: the Icelandic Sleep Apnea Cohort study. Int J Obes (Lond) (2005). 2013;37(6):835.

16. Tungtrongchitr R, Pongpaew $\mathrm{P}$, Tongboonchoo $\mathrm{C}$, Vudhivai N, Changbumrung S, Tungtrongchitr A, et al. Serum homocysteine, B12 and folic acid concentration in Thai overweight and obese subjects. Int J Vitam Nutr Res. 2003;73(1):8-14.

17. Narin F. leptin and apolipoprotein B levels in childhood obesity. Ann Saudi Med. 2005;25(3):209-14.

18. Maffei M, Halaas J, Ravussin E, Pratley R, Lee G, Zhang Y, et al. Leptin levels in human and rodent: measurement of plasma leptin and ob RNA in obese and weight-reduced subjects. Nature. 1995;1(11):1155-61.

19. Yamagishi SI, Edelstein D, Du XL, Kaneda Y, Guzmán M, Brownlee M. Leptin induces mitochondrial superoxide production and monocyte chemoattractant protein-1 expression in aortic endothelial cells by increasing fatty acid oxidation via protein kinase A. J Biol Chem. 2001;276(27):25096-100.

20. Tawakol A, Omland T, Gerhard M, Wu JT, Creager MA. Hyperhomocyst (e) inemia is associated with impaired endothelium-dependent vasodilation in humans. Circulation. 1997;95(5):1119-21.

21. Rexrode KM, Pradhan A, Manson JE, Buring JE, Ridker PM. Relationship of total and abdominal adiposity with CRP and IL-6 in women. Ann Epidemiol. 2003;13(10):674-82.

22. Park HS, Park JY, Yu R. Relationship of obesity and visceral adiposity with serum concentrations of CRP, TNF- $\alpha$ and IL-6. Diabetes Res Clin Pract. 2005;69(1):2935.

23. Sharma S, Mishra HK, Sharma H, Goel A, Sreenivas $\mathrm{V}$, Gulati V, et al. Obesity, and not obstructive sleep apnea, is responsible for increased serum hs-CRP levels in patients with sleep-disordered breathing in Delhi. Sleep med. 2008;9(2):149-56. 
24. Forouhi N, Sattar N, McKeigue P. Relation of Creactive protein to body fat distribution and features of the metabolic syndrome in Europeans and South Asians. Int J Obes (Lond). 2001;25(9).

25. Sanip Z, Ariffin FD, Al-Tahami BAM, Sulaiman WAW, Rasool AHG. Obesity indices and metabolic markers are related to hs-CRP and adiponectin levels in overweight and obese females. Obes Res Clin Pract. 2013;7(4):e315-e20.

26. Maachi M, Pieroni L, Bruckert E, Jardel C, Fellahi S, Hainque B, et al. Systemic low-grade inflammation is related to both circulating and adipose tissue $\mathrm{TNF} \alpha$, leptin and IL-6 levels in obese women. Int J Obes (Lond). 2004;28(8):993-7.

27. Yang RZ, Lee MJ, Hu H, Pollin TI, Ryan AS, Nicklas BJ, et al. Acute-phase serum amyloid A: an inflammatory adipokine and potential link between obesity and its metabolic complications. PLoS Med. 2006;3(6):e287.

28. Van Dielen F, Van't Veer C, Schols A, Soeters P, Buurman W, Greve J. Increased leptin concentrations correlate with increased concentrations of inflammatory markers in morbidly obese individuals. Int $\mathrm{J}$ Obes (Lond). 2001;25(12).

29. Jousilahti P, Salomaa V, Rasi V, Vahtera E, Palosuo T. The association of c-reactive protein, serum amyloid a and fibrinogen with prevalent coronary heart diseasebaseline findings of the PAIS project. Atherosclerosis. 2001;156(2):451-6.

30. Thorn C, Lu ZY, Whitehead A. Regulation of the Human Acute Phase Serum Amyloid A Genes by Tumour Necrosis Factor- $\alpha$, Interleukin- 6 and Glucocorticoids in Hepatic and Epithelial Cell Lines. Scand J Immunol. 2004;59(2):152-8.

31. Poitou C, Viguerie N, Cancello R, De Matteis R, Cinti $\mathrm{S}$, Stich V, et al. Serum amyloid A: production by human white adipocyte and regulation by obesity and nutrition. Diabetologia. 2005;48(3):519-28.

32. Hernandez-Guerrero C, Garcia-Del Rio S, RomoPalafox I, Hernandez-Chavez P, de Oca RZM, PerezLizaur A. Dietary intake of antioxidant nutrients and peripheral plasma determination of T-BARS in normal weight and obese Mexican people (830.14). FASEB J. 2014;28(1 Supplement):830.14.

33. D’Archivio M, Annuzzi G, Varì R, Filesi C, Giacco R, Scazzocchio B, et al. Predominant role of obesity/insulin resistance in oxidative stress development. Eur J Clin Invest. 2012;42(1):70-8.

34. Radziavicius CC, Radziavicius FR, Pereira EC, Azzalis LA, Castelo PM, Junqueira VB, et al. Inflammatory markers, tbars and vitamin $\mathrm{E}$ in class II and III obese patients before undergoing bariatric surgery. Int Arch Med. 2015;8.

35. Tungtrongchitr R, Pongpaew P, Phonrat B, Tungtrongchitr A, Viroonudomphol D, Vudhivai N, et al. Serum copper, zinc, ceruloplasmin and superoxide dismutase in Thai overweight and obese. J Med Assoc Thai 2003;86(6):543-51.

36. Weigle DS, Cummings DE, Newby PD, Breen PA, Frayo RS, Matthys CC, et al. Roles of leptin and ghrelin in the loss of body weight caused by a low fat, high carbohydrate diet. J Clin Endocrinol Metab. 2003;88(4): 1577-86.

37. Blanca AJ, Ruiz-Armenta MV, Zambrano S, Salsoso R, Miguel-Carrasco JL, Fortuño A, et al. Leptin Induces Oxidative Stress through Activation of NADPH Oxidase in Renal Tubular Cells: Antioxidant Effect of LCarnitine. J Cell Biochem. 2016.

38. Tokarz P, Kaarniranta K, Blasiak J. Role of antioxidant enzymes and small molecular weight antioxidants in the pathogenesis of age-related macular degeneration (AMD). Biogerontology. 2013;14(5):461-82.

39. Johnson P. Antioxidant enzyme expression in health and disease: effects of exercise and hypertension. Comp Biochem Physiol C Toxicol Pharmacol. 2002; 133(4):493-505. 